\title{
Endobronchial Metastasis from Testicular Seminoma
}

\author{
Savaş Özsu ${ }^{a}$ M. Muharrem Erol ${ }^{b}$ Funda Öztuna $^{a}$ Şafak Ersöz $^{c}$ Halil Kavgacı $^{d}$ \\ Hamit Z. Aksoy ${ }^{\mathrm{e}}$ \\ Departments of a Chest Diseases, ${ }^{b}$ Thoracic Surgery, ${ }^{c}$ Pathology, ${ }^{d}$ Medical Oncology and ${ }^{\text {e Urology, }}$ \\ School of Medicine, Karadeniz Technical University, Trabzon, Turkey
}

\section{Key Words}

Endobronchial metastasis - Pulmonary metastasis ·

Seminoma

\begin{abstract}
Objective: To present a case of endobronchial metastasis from a seminoma mimicking a primary pulmonary mass on $\mathrm{X}$-ray radiograph. Clinical Presentation and Intervention: A 27-year-old man presented with a 1-month history of hemoptysis. Thorax computerized tomography of the patient obtained at the level of the main right bronchi demonstrated a mass with a size of $7 \times 6 \mathrm{~cm}$ and a peripheral lobulated nodule. Bronchoscopic examination showed narrowing and multiple nodules in the right upper and right intermediary lobar bronchi. Histopathological examination of bronchial biopsies and brushing confirmed endobronchial metastasis of the testicular seminoma. Conclusion: This case shows the prognostic significance of distinguishing endobronchial metastasis from primary lung carcinoma.
\end{abstract}

Copyright $\odot 2008$ S. Karger AG, Base

\section{Introduction}

Endobronchial metastasis (EBM) from extrapulmonary primary malignancy is uncommon. The prevalence of EBM is variable, ranging from 2 to $28 \%$ of pulmonary metastases from extrathoracic neoplasms [1,2]. A variety of primary tumors have been associated with EBM; especially breast, colon, and renal carcinomas predominate $[1,3]$. Although mediastinal nodal enlargements are frequent with testicular seminoma, EBM from the semino$\mathrm{ma}$ is rare. In this report, we presented a case of EBM from a testicular seminoma with a brief review of the literature.

\section{Case Report}

A 27-year-old man presented with a 1-month history of hemoptysis. His medical history was remarkable for right orchiectomy due to testicular seminoma (stage 1) 40 months previously. He was a smoker with 10 pack-years. The patient appeared comfortable, and his vital signs and physical examination were normal. The relevant laboratory findings on admission were: hemoglobin 13.6 $\mathrm{g} / \mathrm{dl}$, hematocrit $40.2 \%$, platelets $340,000 / \mathrm{mm}^{3}$, leukocytes $6,800 /$ $\mathrm{mm}^{3}$ and erythrocyte sedimentation rate $66 \mathrm{~mm} / \mathrm{h}$. Serum chemistry, renal function, liver functions, and urinalysis were normal. $\beta$-hCG was $8.64 \mathrm{mIU} / \mathrm{ml}$ (normal <5.3). Chest radiograph revealed right hilar enlargement and a neighboring nodule. Computerized tomography of the thorax obtained at the level of the main right bronchi demonstrated a mass with a size of $7 \times 6 \mathrm{~cm}$ and a peripheral lobulated nodule (fig. 1). Fiber-optic bronchoscopy showed multiple nodules around the orifice of the right upper lobe and right intermediary lobe and endobronchial narrowing (fig. 2a, b). Histopathological examination of bronchial biopsies and brushing confirmed EBM of the testicular seminoma and immunohistochemical staining was strongly positive for CD117

\section{KARGER}

Fax +4161306 1234 E-Mail karger@karger.ch www.karger.com
(C) 2008 S. Karger AG, Base

1011-7571/08/0176-0493\$24.50/0

Accessible online at:

www.karger.com/mpp
Dr. Savaș Özsu

Department of Chest Diseases, School of Medicine

Karadeniz Technical University

TR-61080 Trabzon (Turkey)

Tel. +90 462377 5402, Fax +90 462325 7031, E-Mail savoz@mynet.com 
(fig. 3a, b). There was no evidence of any other distant metastasis. Abdominal CT did not show lymph node enlargement. Three months after four cycles of chemotherapy (cisplatin, etoposide and bleomycin in combination) control thorax CT was completely normal. The patient was followed up clinically and radiographically for 8 months with no evidence of disease recurrence.

\section{Discussion}

Lung metastases from extrapulmonary primary malignancies are common. However EBM are uncommon and they usually mimic primary pulmonary carcinoma. A variety of primary tumors have been associated with EBM, especially breast, colon, and renal carcinomas predominate $[1,3]$. EBM from testicular seminoma is extremely rare. Only two previous reports of primary testicular seminoma producing EBM have been published $[4,5]$.

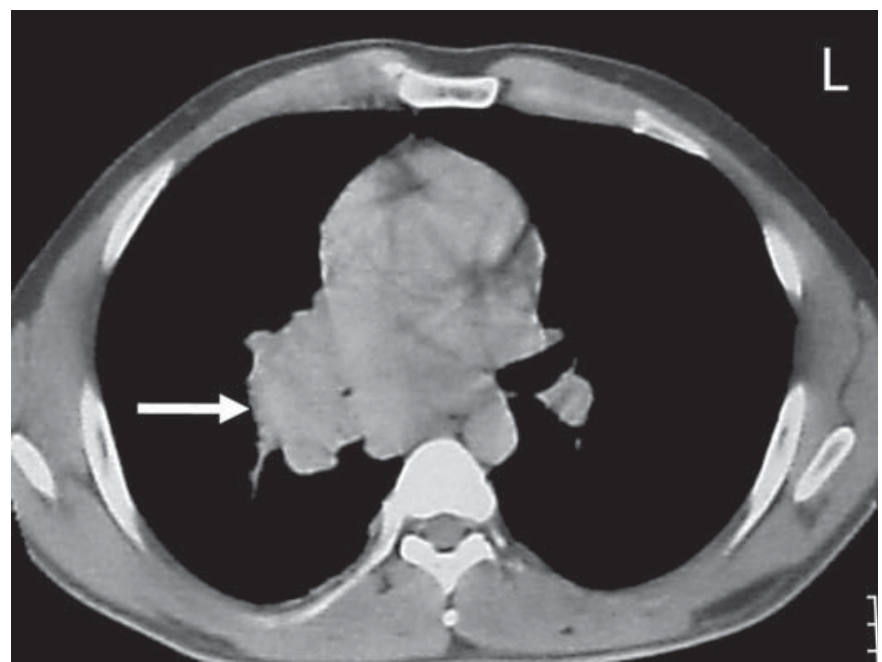

Fig. 1. A mass with a size of $7 \times 6 \mathrm{~cm}$ at the level of the right main bronchi (arrow).
Fig. 2. Bronchoscopic appearance of the lesion; multiple nodules were seen on the bronchial surface around the orifice of the right upper lobe bronchi and the right intermediary lobe (arrows) (a) as well as endobronchial narrowing (arrows) (b).

Fig. 3. a Bronchoscopic mucosal biopsy demonstrating a relationship between lymphocytes (white arrow) and atypical germ cells with large hyperchromatic nuclei (black arrow) and evident nucleoli. HE. $\times 400$. b Immunohistochemical examination with CD117 shows cytoplasmic membranous staining (black arrow). IHC. $\times 400$.
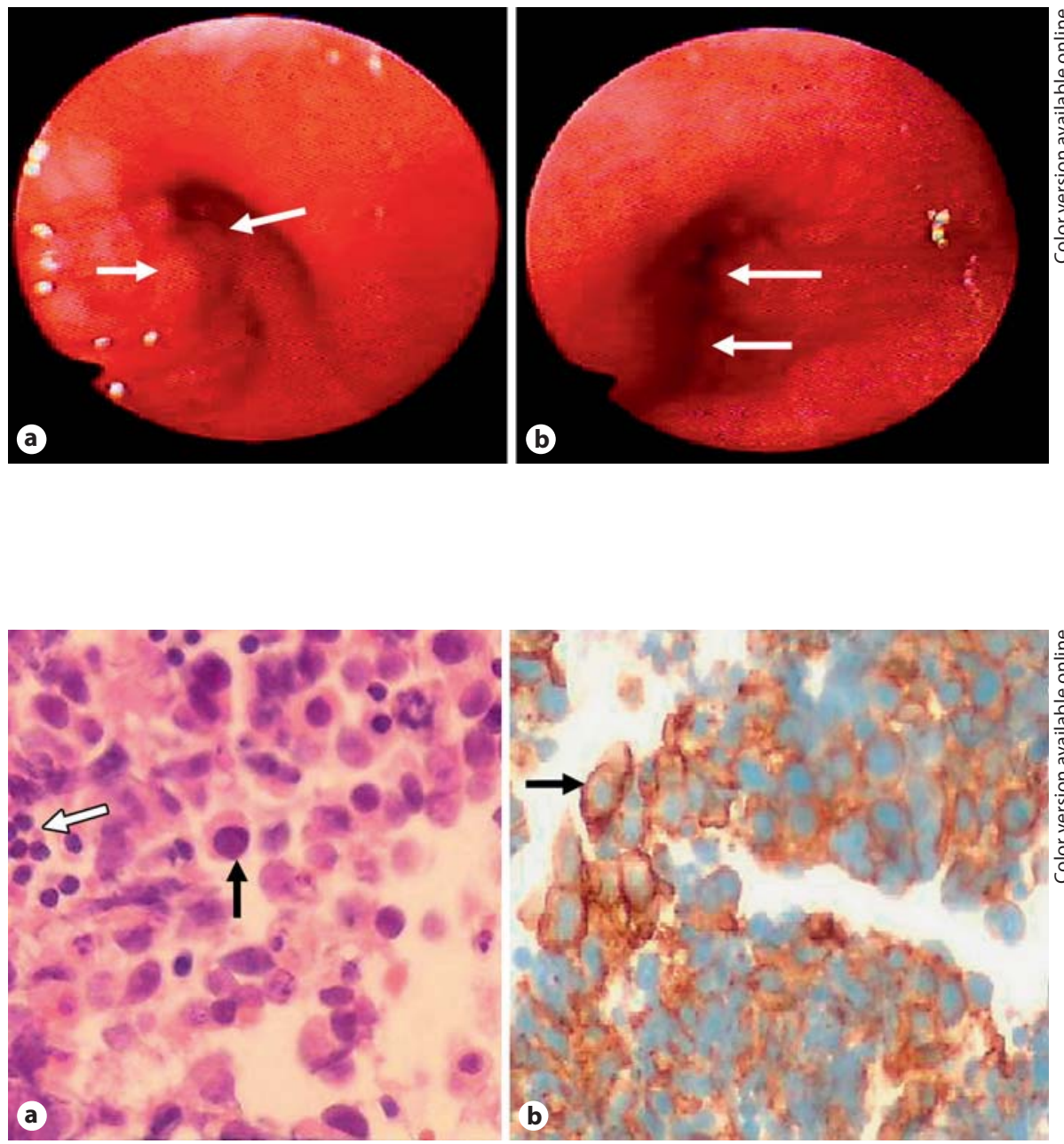
Extrapulmonary malignancies are assumed to spread to the EBM by different routes [6-8]. Secondary invasion from a parenchymal or mediastinal lesion, direct lymphatic spread, transbronchial aspiration or direct invasion are possible routes [6]. Metastatic spread of seminoma generally occurs by way of the lymphatic system to the retroperitoneal lymph nodes. Visceral metastasis when present occurs most often in the lungs, liver, and brain [7]. Pulmonary metastases are observed in approximately $15 \%$ of patients with testicular seminoma [8].

Symptoms in patients with EBM are similar to those associated with primary bronchogenic carcinoma. The most common symptoms are coughing and hemoptysis, with dyspnea and wheezing occurring less often [3, 9]. However, some patients are asymptomatic. In several series it has been reported that $16-62.5 \%$ of patients were asymptomatic at the time of diagnosis [3,9], but in our patient the unique symptom on admission was hemoptysis.

Chest radiographs in patients with EBM are quite variable. Patients may present with evidence of atelectasis, multiple pulmonary nodules, hilar masses, mediastinal lymphadenopathy, or normal chest radiographic findings. On the other hand, mediastinal nodal enlargement is the most common intrathoracic manifestation of metastatic testicular seminoma [9]. As a result, it is difficult to differentiate between diagnoses of primary lung carcinoma and EBM on the basis of the symptoms and radiographic findings alone. Histopathological examination and immunohistochemical staining is the backbone of definitive diagnosis of metastatic testicular seminoma as in our patient.

The time interval between diagnosis of the primary tumor and the EBM is generally long. The published interval from diagnosis of the primary tumor to the development of EBM ranges from 0 to 65 months [3]. The survival time is variable according to the primary tumor, but prognosis is generally poor. However, 5 -year survival in metastatic testicular carcinoma is approximately $82 \%$ in patients with only lung or lymph node involvement [10].

\section{Conclusion}

This case shows the importance of distinguishing EBM from primary lung carcinoma because seminoma involves a different therapeutic approach and survival expectation.

\section{References}

-1 Braman SS, Whitcomb ME: Endobronchial metastasis. Arch Intern Med 1975;135:543547.

-2 Shepherd MP: Endobronchial metastatic disease. Thorax 1982;37:362-365.

>3 Kiryu T, Hoshi H, Matsui E, Iwata H, Kokuba M, Shimokawa K, Kawaguchi S: Endotracheal/endobronchial metastases. Chest 2001; 119:768-775
4 Varma VA, Lipper S, Kahn SB: Endobronchial metastasis from testicular seminoma. Arch Pathol Lab Med 1981;105:680.

5 Suito T, Ishihara T, Yamazaki S, Fukai S, Kaseda S, Suzuki T, Kikuchi K, Nomoto E, Hanaoka K, Kobayashi K: Endobronchial metastasis of testicular embryonal cell carcinoma - a case report. Gan No Rinsho 1983; 29:1340-1343.

6 Fitzgerald RH: Endobronchial metastasis South Med J 1977;70:440-441.

7 Farnham SB, Mason SE, Smith JA Jr: Metastatic testicular seminoma to the prostate. Urology 2005;66:28-30. $\checkmark 8$ Williams MP, Husband JE, Heron CW: Intrathoracic manifestations of metastatic testicular seminoma: a comparison of chest radiographic and CT findings. Am J Roentgenol 1987;149:473-475.

-9 Akoglu S, Ucan ES, Celik G, Sener G, Sevinc C, Kilinc O, Itil O: Endobronchial metastases from extrathoracic malignancies. Clin Exp Metastasis 2005;22:587-591.

10 International Germ Cell Consensus Classification: a prognostic factor-based staging system for metastatic germ cell cancers. International Germ Cell Cancer Collaborative Group. J Clin Oncol 1997;15:594-603. 